\title{
Effect of yeast culture supplementation on carcass yield and humoral immune response of broiler chicks
}

\author{
M M Fathi, S Al-Mansour, A Al-Homidan, A Al-Khalaf , M Al-Damegh ${ }^{1}$ \\ College of Agriculture and Veterinary Medicine, Qassim University, Saudi Arabia; \\ 1. Department of Biology, College of Science and Arts, Qassim University, Saudi Arabia \\ Corresponding author: M M Fathi, email:mmfathi@fulbrightmail.org, \\ Cell: +966594067644, Fax: +96663801360 \\ Received: 07-04-2012, Accepted: 18-05-2012, Published Online:15-09-2012 \\ doi: $10.5455 /$ vetworld.2012.651-657
}

\begin{abstract}
Aim: A study was conducted to evaluate the effect of supplemental yeast culture (Diamond V XPC Yeast Culture; YC) in broiler diets on carcass characteristics and humoral immune response.

Materials and Methods: A total of 240 one-day-old broiler chicks (Ross 308) were randomly assigned to four YC dietary treatments of 60 birds each. The dietary treatments were 0 (control), $1,1.25$ and $1.5 \mathrm{~g} \mathrm{YC} / \mathrm{kg}$ diet over $42 \mathrm{~d}$.

Results and Discussion: The results revealed that the birds fed yeast cultures had statistically increased $(P<0.05)$ body weight from control birds only at 5-6 weeks of age. The highest inclusion level $(1.5 \mathrm{~g} / \mathrm{kg})$ recorded the best weight. The broiler chicks fed a diet supplemented with $1.25 \mathrm{~g} / \mathrm{kg}$ had the lowest mortality rate over the whole period of the experiment. The birds given the highest level of yeast $(1.5 \mathrm{~g} / \mathrm{kg})$ had significantly $(\mathrm{P}<0.05)$ higher percentage of major and minor breast muscles compared with the others that fed a basal diet. A significantly $(\mathrm{P}<0.01)$ increase in IgM titer was noticed in birds fed diet containing YC levels more than $1 \mathrm{~g} / \mathrm{kg}$ at 7 days post-injection with sheep red blood cells. Likewise, broilers fed a diet containing $1.25 \mathrm{~g} / \mathrm{kg}$ exhibited a higher level of antibody titer against Newcastle disease virus at latter age (on d 42) compared with the other groups.

Conclusion: The data suggest improvement in growth performance, carcass yield and humoral immunity of broilers fed yeast culture supplementation diet.

Key words: broiler, carcass, humoral immunity, yeast
\end{abstract}

To cite this article: Fathi MM, Al-Mansour S, Al-Homidan A, Al-Khalaf A, Al-Damegh M (2012) Effect of yeast culture supplementation on carcass yield and humoral immune response of broiler chicks, Vet World, 5(11): 651-657, doi: 10.5455/vetworld.2012.651-657

\section{Introduction}

In recent years, there has been a great attention to minimize or completely avoid usage of antibiotics in both animal and poultry feeding, as well as an increasing consumer concern for poultry drug residues in meat and eggs. In 2006, the European Union imposed a complete ban on the use of antibiotics in animal feed as growth promotants. As these bans are being considered, non-antibiotic alternatives like yeast and yeast products are widely used in poultry rations to improve growth and productive performance. Effects of yeast products on production and their mode of action in poultry have been reported [1]. Whole yeast products or yeast cell wall components have been used to improve growth and affect the physiology, morphology, and microbiology of the intestinal tract of both broiler chicks [1-9] and turkey poults [10-15]. Likewise, inclusion of yeast in the diet has been shown to improve livability and decrease mortality [16].
Many other beneficial factors of yeast inclusion such as improved carcass development and breast yield were intensively reported. Higher muscle percentage of many parts of carcass was observed [4,9,17-19]. On the other hand, some researchers didn't find an advantage of dietary yeast inclusion on carcass measurements $[20,21]$. Use of yeast and yeast products as natural growth promoters and immunomodulators is well documented. It may serve as alternatives to antibiotics for both growth promotion and disease resistance in poultry production. Several literature referred that supplementation of yeast products improved immune response [2, 22-25].

The purpose of the present study was to examine the effect of different dietary concentrations of yeast culture on growth performance, carcass yield and humoral immunity in broiler chicks.

\section{Materials and Methods}

Ethical approval: Use of birds in this study was approved by the Institutional Animal Ethical Committee. 
Birds, management, and experimental Design: A total of 240 one-day-old broiler chicks (Ross 308) were purchased from a commercial supplier. The chicks were housed in poultry research station at Qassim University (Saudi Arabia) and randomly assigned to four dietary treatments with similar average initial weight of 60 birds each. Each treatment was allotted to 4 caged replicates (each having 15 chicks). The dietary treatments consisted of the basal diet supplemented with increasing level of Yeast Culture (YC); 0 (control), 1, 1.25 (recommended level) and $1.5 \mathrm{~g} / \mathrm{kg}$. The coarse powder of yeast culture used was obtained from Diamond V Mills, Cedar Rapids, IA, USA. The birds were fed a corn-soybean meal starter diets containing $21.5 \%$ crude protein and 3000 $\mathrm{Kcal} \mathrm{ME} / \mathrm{Kg}$ diet until $21 \mathrm{~d}$ of age followed by a finishing diet containing $19.0 \%$ crude protein and $3200 \mathrm{Kcal} \mathrm{ME} / \mathrm{Kg}$ diet from day 21 to day 42. Respective amounts of yeast were first mixed with small amounts $(100 \mathrm{~g})$ of the basal diets, then with a larger amount of the diet until the total amount of the respective diets were homogeneously mixed. No antibiotics were included in the experimental diets of the current study. Environmental conditions were controlled by a computer system according to the standard recommendations for broiler chicks. All birds were kept under the same managerial, environmental and hygienic conditions except for different dietary levels of yeast. Birds were provided with continuous light. Feed and fresh water were available for ad libitum consumption throughout the $42 \mathrm{~d}$ of the experiment. Upon arrival, the temperature inside the house was adjusted to $32 \mathrm{C}$ at the first day and was then reduced by $2.5^{\circ} \mathrm{C}$ each week. The mean value of daily temperature inside the house throughout the whole experimental period was $25 \pm 1^{\circ} \mathrm{C}$.

Growth performance and mortality rate: Body weight in gram was weekly determined until the end of the experiment on individual basis. Mortality was daily recorded, then mortality rate was calculated over 42 days.

Antibody titer against newcastle disease virus: Broilers were vaccinated with Newcastle disease "LaSota" vaccine (Intervet International B.V., Boxmeer, Holland) via drinking water on d 10 and 28. Three birds from each replicate within each treatment were randomly selected and blood was collected from the wing vein. The sera were stored at $-20^{\circ} \mathrm{C}$ until the end of the experiment. Antibody titer against Newcastle disease virus (NDV) was determined by Haemagglutination Inhibition (HI) test on d 28, 35 and 42. The data were expressed as the logarithm base 2 .

\section{Antibody response against Sheep red blood cells} (SRBC): Sheep red blood cells (SRBC) were used as T-dependent antigens to quantify the antibody response. At 3 weeks of age, three birds from each replicate within each treatment were injected intramuscularly with SRBC (7\% suspension in PBS, 1 $\mathrm{ml} / \mathrm{bird}$ ). Blood samples were collected at 7, 14 and 21 days after injection. The serum from each sample was harvested and stored at $-20^{\circ} \mathrm{C}$ until tested. Serum was heat inactivated at $56^{\circ} \mathrm{C}$ for $30 \mathrm{~min}$ and then analyzed for total, mercaptoethanol-sensitive (MES) IgM and mercaptoethanol-resistant IgG anti-SRBC antibodies as previously described [26,27]. Titers were expressed as the $\log _{2}$ of the reciprocal of the highest dilution giving complete agglutination. The difference between the total and the IgG response was considered to be the IgM antibody level.

Carcass dissection: At the end of the experiment, 12 chicks from each dietary treatment were selected and slaughtered for carcass evaluation. Birds were individually weighed before slaughter. They were sacrificed by exsanguination and leaved to complete bleeding. Feathers were manually removed after scalding at $60^{\circ} \mathrm{C}$ for approximate $2 \mathrm{~min}$. The bird was processed by removing the head, shanks and feet and eviscerated by removing the viscera. The heart and liver were dissected from the viscera and the gizzard was cut open and rinsed of its contents. Also, bursa of Fabricius and spleen were removed and weighed. The carcass was then immersed in cold water. The carcass, thigh, drumstick and breast muscles (minor and major) were weighed. Each portion was expressed as a proportion of the live body weight.

Statistical analysis: Data were subjected to a oneway ANOVA using JMP Ver. 8.0.1 [SAS Institute, 28] with dietary treatment as a fixed effect. All results are presented as mean and the pooled SEM. The significance of difference among the groups was assessed using Duncan's new multiple range test. Significance was set as $\mathrm{P}<0.05$.

\section{Results and Discussion}

Body weight and mortality rate: The results of body weight for each supplemented group are presented in Table1. As noticed, body weight of broiler chicks during earlier ages (through the first four weeks) didn't significantly improve by the dietary inclusion of yeast culture, suggesting that yeast culture didn't play an active role in body weight during the initial stage of growth period. Similarly, Fasina and Thanissery [29] observed that the body weight of yeast 
Effect of yeast culture supplementation on carcass yield and humoral immune response of broiler chicks

Table 1. Effect of supplemental yeast culture in broiler diets on live body weight in $\mathrm{g}$

\begin{tabular}{lllllll}
\hline Age & Treatment & $\mathbf{1 g} / \mathbf{k g}$ & $\mathbf{1 . 2 5} \mathbf{g} \mathbf{k g}$ & $\mathbf{1 . 5 g} / \mathbf{k g}$ & $\mathbf{S E M}$ & $\mathbf{P}$ \\
\hline $1 \mathrm{wk}$ & 202.4 & 201.8 & 209.3 & 204.0 & 3.54 & NS \\
$2 \mathrm{wk}$ & 386.9 & 381.6 & 395.4 & 402.3 & 7.23 & NS \\
$3 \mathrm{wk}$ & 717.5 & 749.5 & 750.0 & 742.6 & 15.5 & NS \\
$4 \mathrm{wk}$ & 1082.0 & 1112.8 & 1109.1 & 1139.0 & 22.3 & NS \\
$5 \mathrm{wk}$ & $1593.5^{\mathrm{c}}$ & $1640.4^{\mathrm{cb}}$ & $1700.5^{\mathrm{b}}$ & $1782.8^{\mathrm{a}}$ & 49.6 & 0.05 \\
$6 \mathrm{wk}$ & $2318.6^{\mathrm{b}}$ & $2569.3^{\mathrm{ab}}$ & $2690.3^{\mathrm{a}}$ & $2769.5^{\mathrm{a}}$ & 58.23 & 0.03 \\
\hline
\end{tabular}

a-c Means within a row within titer with no common superscript differ significantly.

Table 2. Effect of supplemental yeast culture in diet on carcass characteristics of 42 -day-old broilers

\begin{tabular}{lllllll}
\hline Trait, \% & Treatment & & & & \\
& $\mathbf{0}$ & $\mathbf{1 g} / \mathbf{k g}$ & $\mathbf{1 . 2 5} \mathbf{k g}$ & $\mathbf{1 . 5} \mathbf{g} \mathbf{k g}$ & $\mathbf{S E M}$ & $\mathbf{P}$ \\
\hline Carcass & 70.49 & 72.33 & 71.49 & 72.34 & 0.47 & 0.47 \\
Spleen & 0.16 & 0.16 & 0.15 & 0.19 & 0.01 & 0.56 \\
Bursa & 0.09 & 0.07 & 0.05 & 0.06 & 0.01 & 0.26 \\
Liver & 2.01 & 1.94 & 1.80 & 1.90 & 0.05 & 0.56 \\
Heart & 0.48 & 0.45 & 0.48 & 0.47 & 0.01 & 0.75 \\
Gizzard & 1.31 & 1.26 & 1.22 & 1.22 & 0.02 & 0.55 \\
Thigh & 6.54 & 7.06 & 8.70 & 7.16 & 0.40 & 0.27 \\
Drum Stick & 4.55 & 4.73 & 4.73 & 4.81 & 0.12 & 0.89 \\
Major Pectoralis & $7.21^{\mathrm{b}}$ & $7.85^{\mathrm{ab}}$ & $7.23^{\mathrm{b}}$ & $8.44^{\mathrm{a}}$ & 0.18 & 0.04 \\
Minor Pectoralis & $1.67^{\mathrm{b}}$ & $1.75^{\mathrm{b}}$ & $1.79^{\mathrm{ab}}$ & $1.90^{\mathrm{a}}$ & 0.03 & 0.02 \\
\hline
\end{tabular}

a-c Means within a row within titer with no common superscript differ significantly.

supplemented group of chicks hatched from young breeder hens didn't differ from the chicks of unsupplemented group. It should be noted that the inclusion of yeast in broiler's ration with $1.25 \mathrm{~g} / \mathrm{kg}$ or $1.5 \mathrm{~g} / \mathrm{kg}$ significantly $(\mathrm{P}<0.05)$ improved body weight particularly in latter ages (5 and 6 weeks of age) compared with control one. These results confirmed findings described previously by several researchers $[1,9,36,39,40]$. Furthermore, Chae et al. [37], MoralesLopez et al. [38] and Zhang et al. [25] concluded that supplementation of broiler chicken diets with yeast culture wall or purified fractions has resulted in improvements of both body weight gain and feed efficiency. On the other hand, Morales-Lopez et al. [7] evaluated the effect of various yeast cell wall components on growth performance parameters in broiler chicks, but found no effect. Perhaps the components of a yeast product influence the efficacy of yeast (and yeastcontaining products) as growth promoters, and, if so, each yeast product formulation must be evaluated for efficacy as a non-antibiotic promoters.

Another interesting point noticed from many previous reports is that the effective inclusion levels reported for a yeast product are different $(0.25 \%$ yeast culture, Gao et al., [23], 2\% Alphamune yeast extract, Solis de los Santos et al., [14], 0.075\% novel yeast product, Fasina and Thanissery, [29]). However, many researchers attributed the different response of birds to the yeast supplementation due to the nature of the experiment conditions. It has been reported that in order for the yeast products to be effective, the birds need to be kept under stress in some way [30].

As illustrated in Figure 1. The broiler chicks fed a diet supplemented with recommended level $(1.25 \mathrm{~g} / \mathrm{kg})$ recorded the lower mortality rate over the whole period of the experiment. The last observation is in harmony with the findings of Silva et al., [16] and Hosseini [9] who stated that the addition of yeast extract to broiler diets promoted better feed conversion and better livability at $21 \mathrm{~d}$ of age. Similarly, Tangendjaja and Yoon [31] found that yeast culture supplementation reduced mortality in laying hens. However, studies investigating the mechanisms of yeast action on health and/or immunity are limited.

Carcass Characteristics: The effect of feeding different levels of yeast on dressing carcass, breast, leg and some internal organs percentages are summarized in Table 2. The results showed that the inclusion of yeast slightly improved carcass percentage. Also, an increase in thigh percentage was detected for chicks fed a diet supplemented with yeast. Moreover, the recommended level recorded the highest percentage. In terms of breast muscles, it could be observed that 


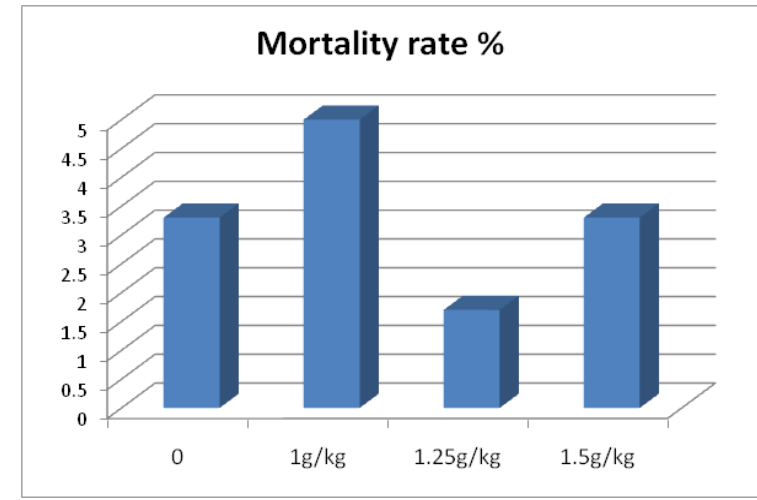

Figure-1. Cumulative mortality rate over 42-day of age the birds given the highest level of yeast $(1.5 \mathrm{~g} / \mathrm{kg})$ had significantly $(P<0.05)$ higher percentage of major and minor breast muscles compared with others that fed a basal diet. Likewise, Hosseini [9] found a significant percentage of carcass, liver, heart and gizzard in broilers fed ration containing Saccharomysec Cerevisiaet compared to untreated siblings. Miazzo et al. [18] also reported that the broiler fed yeast $(0.3 \%)$ had a higher leg muscle than the other group fed a basal diet without yeast inclusion. Onifade, [17] found that the broiler chicks fed dried yeast had a significantly greater weight of liver, spleen and gizzard compared to the control siblings.

In broilers fed yeast extract (nucleotide source), Rutz et al. [4] observed a numerical improvement in carcass yield, as well as in drum, thigh, wing and breast yields as compared to birds that did not receive yeast extract. Similarly, broiler chicks fed a diet containing enzymatically hydrolyzed yeast at a rate of $1 \%$ significantly improved yield of the carcass, breast and legs [19]. In the other hand, Karaoglu and Durdag, [20] and Chumpawadee et al. [21] found that yeast (Sacharomyces cerevisiae) supplementation in broiler's diet did not have any effect on hot carcass or cold carcass percentage. There was no effect of nucleotides on carcass and parts yields of broilers given a diet containing nucleotides at levels varying
Table-3. Antibody responses against SRBC expressed as total antibody titres, mercaptoethanolresistant titres (IgG) and mercaptoethanol-sensitive titres (IgM) concentrations in different supplemented groups.

\begin{tabular}{lccc}
\hline Supplementation level & 7 Day-PI & 14 Day-PI & 21 Day-PI \\
\hline Total anti-SRBC antibody titer & & & \\
0 & $3.4^{\mathrm{b}}$ & $2.3^{\mathrm{b}}$ & $1.6^{\mathrm{b}}$ \\
$1 \mathrm{~g} / \mathrm{kg}$ & $4.1^{\mathrm{a}}$ & $3.3^{\mathrm{a}}$ & $2.4^{\mathrm{a}}$ \\
$1.25 \mathrm{~g} / \mathrm{kg}$ & $4.4^{\mathrm{a}}$ & $2.8^{\mathrm{ab}}$ & $2^{\mathrm{ab}}$ \\
$1.5 \mathrm{~g} / \mathrm{kg}$ & $4^{\mathrm{a}}$ & $2.8^{\mathrm{ab}}$ & $1.5^{\mathrm{b}}$ \\
$\mathrm{SEM}$ & 0.13 & 0.12 & 0.13 \\
$\mathrm{P}$ & 0.03 & 0.02 & 0.05 \\
IgG anti-SR BC antibody titer & & & \\
0 & 1.8 & 1.1 & 0.4 \\
$1 \mathrm{~g} / \mathrm{kg}$ & 2.4 & 1.7 & 0.6 \\
$1.25 \mathrm{~g} / \mathrm{kg}$ & 2.1 & 1 & 0.5 \\
$1.5 \mathrm{~g} / \mathrm{kg}$ & 1.8 & 1.3 & 0.5 \\
$\mathrm{SEM}$ & 0.11 & 0.09 & 0.10 \\
$\mathrm{P}$ & 0.16 & 0.13 & 0.97 \\
IgM anti-SRBC antibody titer & & & \\
0 & $1.6^{\mathrm{c}}$ & 1.2 & 1.1 \\
$1 \mathrm{~g} / \mathrm{kg}$ & $1.8^{\mathrm{bc}}$ & 1.7 & 1.8 \\
$1.25 \mathrm{~g} / \mathrm{kg}$ & $2.3^{\mathrm{a}}$ & 1.8 & 1.5 \\
$1.5 \mathrm{~g} / \mathrm{kg}$ & $2.2^{\mathrm{ab}}$ & 1.5 & 1 \\
$\mathrm{SEM}$ & 0.08 & 0.09 & 0.14 \\
$\mathrm{P}$ & 0.01 & 0.17 & 0.19 \\
\hline
\end{tabular}

abc Means within a column within titer with no common superscript differ significantly.

$\mathrm{PI}=$ post SRBC-injection

from $0.04-0.07 \%$ [32].

Antibody Response to SRBC: Antibody titer responses have been used as measures of humoral immune status of birds [33]. Total IgG and IgM antibody concentrations against SRBC were presented in Table 3. It could be observed that the birds fed a diet containing $\mathrm{YC}$ at the rate of $1 \mathrm{~g} / \mathrm{kg}$ had significantly $(\mathrm{P}<0.05)$ higher total antibodies at all tested periods compared with control counterparts. Generally, higher total antibody titer against SRBC in supplemented groups was noticed. Similarly, Asli et al. [34] and Yalcin et al. [35] observed greater antibody production against SRBC in laying hens fed yeast in the diet compared with the control group. This higher antibody titer in laying hens supplemented with yeast autolysate could be explained by the beneficial effects of supplementation in maintaining a physiological balance of immunopotent cells and therefore providing a healthy environment for the immune system.

Another interesting point is that the birds fed YC had an increase in IgM titer particularly at 7 days post inoculation with SRBC. Moreover, the recommended level $(1.25 \mathrm{~g} / \mathrm{kg})$ recorded the highest figure at all tested periods compared to the control group. This result is in agreement with the finding of Gao et al. [23], who found a linearity increased in IgM associated with increasing level of yeast. This implies 
Effect of yeast culture supplementation on carcass yield and humoral immune response of broiler chicks

Table-4. Total anti-NDV antibody titer of commercial broiler strains as affected by yeast supplementation

\begin{tabular}{lllllll}
\hline Age & Treatment & & & & & \\
& $\mathbf{0}$ & $\mathbf{1 g} / \mathbf{k g}$ & $\mathbf{1 . 2 5} \mathbf{g} \mathbf{k g}$ & $\mathbf{1 . 5} \mathbf{g} \mathbf{k g}$ & $\mathbf{S E M}$ & $\mathbf{P}$ \\
\hline Total anti-NDV & antibody titer & & & & & \\
28 & 4.4 & 4.5 & 4.3 & 5.7 & 0.32 & 0.33 \\
35 & 3.6 & 3.8 & 3.5 & 4.8 & 0.26 & 0.28 \\
42 & 4.2 & 4.7 & 6.5 & 5.9 & 0.37 & 0.09 \\
\hline
\end{tabular}

that YC may stimulate the humoral immune system to produce more antibodies. Increased antibodies cover the surface of intestinal mucosa and can protect villi from damage. It was proposed that oligosaccharides in the yeast cell wall could bind to viruses and work as adjuvants of vaccines to increase the titers of antibody in YC-treated birds.

Antibody Titer to NDV: As shown in Table 4, it could be noticed that the higher level of YC inclusion increased total antibodies against NDV. Whereas, the recommended level $(1.25 \mathrm{~g} / \mathrm{kg})$ exhibited the highest titer (almost significant, $\mathrm{P}=0.09$ ) after the second inoculation (on d 42) compared with the other supplemental levels. That is meant the birds given recommended level has a good immune memory cells to reconstitute the same antibodies after inoculation with boost antigen. Gao et al. [23] found that antibody titers to NDV increased linearly when the level of dietary YC increased, which suggests that YC may also influence systemic or humoral immunity of birds. In contrast, Silva et al. [16] stated that the addition of yeast extract in the prestarter phase did not change the humoral immune response against Newcastle disease virus or infectious bursal disease throughout the production cycle of the broilers.

In summary, dietary supplementation with yeast culture at levels of 1.25 , and $1.5 \mathrm{~g} / \mathrm{kg}$ in broiler chicks had beneficial effects on body weight, mortality rate and humoral immunity. Additionally, carcass yield was improved in birds fed a diet supplemented with YC particularly, in thoracic region (breast muscles).

\section{Author's contribution}

Moataz Fathi and Sultan Al-Mansour participated in the preparation of the experimental design. Moataz Fathi analysed data, sample and wrote the final draft of the manuscript. All the authors has read and approved the manuscript.

\section{Acknowledgements}

The authors gratefully acknowledge Diamond V Mills, Cedar Rapids, PO Box 74570, IA 52407, USA for kindly providing us with yeast product.

\section{Competing interest}

Authors declares that they have no competing interest.

\section{References}

1. Zhang, A.W., Lee, B.D., Lee, S.K., Lee, K.W., An, G.H., Song, K.B., Lee, C.H. (2005) Effects of yeast (Saccharomyces cerevisiae) cell components on growth performance, meat quality, and ileal mucosa development of broiler chicks. Poult. Sci. 84: 1015-1021.

2. Hooge, D.M. (2004a) Meta-analysis of broiler chicken pen trials evaluating dietary mannan oligosaccharide. Int. J. Poult. Sci. 3: 163-174.

3. Huff, G.R., Huff, W.E., Rath, N.C., Tellez, G. (2006) Limited treatment with $\beta-1,3 / 1,6$-glucan improves production values of broiler chickens challenged with Escherichia coli. Poult. Sci. 85:613-618.

4. Rutz, F., Anciuti, M.A., Rech, J.L., Gonçalves, F.M., Delgado, A.D., Rosa, E.R., Zauk, N., Ribeiro, C.L.G., Silva, R.R., Dallmann, P.R. (2006) Desempenho e caracteristicas de carcaças de frangos de corte recebendo extrato de levedura na dieta. Ciência Animal Brasileira 7:349-355.

5. Rosen, G.D. (2007a) Holo-analysis of the efficacy of Bio-Mos in broiler nutrition. Br. Poult. Sci. 48:21-26.

6. Yang, Y., Iji, P.A., Kocher, A., Thomson, E., Mikkelsen, L.L., Choct, M. (2008) Effects of mannanoligosaccharide in broiler chicken diets on growth performance, energy utilization, nutrient digestibility, and intestinal microflora. Br. Poult. Sci. 49:186-194.

7. Morales-Lopez, R., Auclair, E., Garcia, F., EsteveGarcia, E., Brufau, J. (2009) Use of yeast cell walls; $\beta$ 1,3/1,6-glucans; and mannoproteins in broiler chicken diets. Poult. Sci. 88:601-607.

8. Al-Mansour, S., Al-Khalf, A., Al-Homidan, I., Fathi, M.M. (2011) Feed efficiency and blood hematology of broiler chicks given a diet supplemented with yeast culture, Int. J. Poult. Sci. 10: 603-607.

9. Hosseini, S. (2011) The effect of utilization of different levels of Saccharomysec cerevisiae on broiler chicken's performance. Global Vet. 6: 233236.

10. Hooge, D.M. (2004b) Turkey pen trials with dietary mannan oligosaccharide: Meta-analysis, 1993-2003. Int. J. Poult. Sci. .3:179- 188.

11. Sims, M.D., Dawson, K.A., Newman, K.E., Spring, P., Hooge, D.M. (2004) Effects of dietary mannan oligosaccharide, bacitracin methylene disalicylate, or 
both on the live performance and intestinal microbiology of turkeys. Poult. Sci. 83:1148-1154.

12. Huff, G.R., Huff, W.E., Rath, N.C., Solis de los Santos, F., Farnell, M.B., Donoghue, A.M. (2007) Influence of hen age on the response of turkey poults to cold stress, Escherichia coli challenge, and treatment with a yeast extract antibiotic alternative. Poult. Sci. 86:636-664.

13. Rosen, G.D. (2007b) Holo-analysis of the efficacy of Bio-Mos in turkey nutrition. Br. Poult. Sci. 48:27-32.

14. Solis de los Santos, F., Donoghue, A.M., Farnell, M.B., Huff, G.R., Huff, W.E., Donoghue, D.J. (2007) Gastrointestinal maturation is accelerated in turkey poults supplemented with a mannanoligosaccharide yeast extract (Alphamune). Poult. Sci. 86:921-930.

15. Huff, G.R., Huff, W.E., Farnell, M.B., Rath, N.C., Solis de los Santos, F., Donoghue, A.M. (2010) Bacterial clearance, heterophil function, and hematological parameters of transport-stressed turkey poults supplemented with dietary yeast extract. Poult. Sci. 89:447-456.

16. Silva, V.K., Della Torre da Silva, J., Torres, K.A.A., de Faria Filho, D.E., Hirota Hada, F., Barbosa de Moraes, V.M. (2009) Humoral immune response of broilers fed diets containing yeast extract and prebiotics in the prestarter phase and raised at different temperatures. J. Appl. Poult. Res. 18:530-540.

17. Onifade, A.A. (1997) Growth performance, carcass characteristics, organs measurement and haematology of broiler chickens fed a high fibre diet supplemented with antibiotics or dried yeast. Nahrung 41:370-374.

18. Miazzo, R.D., Peralta, M.F., Picco, M. (2005) Perfomance productively calidad de la canal en broilers que recibieron lavadara de cerveza $(S$. cerevisiae). Revista Electronica de vet. 12: 1-9.

19. Gomez, S., Angeles, M. (2011) Effects of an enzymatically hydrolyzed yeast and yeast culture combined with flavomycin and monensin on finishing broiler chickens. Int. J. Poult. Sci. 10: 433-439.

20. Karaoglu, M., Durdag, H. (2005) The influence of dietary probiotic (Saccharomyes cerevisiae) supplementation and different slaughter age on the performance, slaughter and carcass properties of broilers. Int. J. Poult. Sci. 4:309-316.

21. Chumpawadee, S., Chinrasri, O., Somchan, T., Ngamluan, S., Soychuta, S. (2008) Effect of dietary inclusion of Cassava Yeast as probiotic source on growth performance, small intestine (ileum) morphology and carcass characteristic in broilers. Int. J. Poult. Sci. 7:246-250.

22. Shashidhara, R.G., Devegowda, G. (2003) Effect of dietary mannan oligosaccharide on broiler breeder production traits and immunity. Poult. Sci. 82: 1319-1325.

23. Gao, J., Zhang, H.J., Yu, S.H., Wu, S.G., Yoon, I., Quigley, J., Gao, Y.P., Qi, G.H. (2008) Effects of yeast culture in broiler diets on performance and immuno- modulatory functions. Poult. Sci. 87:1377-1384.

24. Jensen, G.S., Patterson, K.M., Yoon, I. (2008) Yeast culture has anti-inflammatory effects and specifically activates NK cells. Comp. Immunol. Microbiol. Infect. Dis. 31:487-500.

25. Zhang, S., Liao, B., Li, X., Li, L., Ma, L., Yan, X. (2011) Effects of yeast cell walls on performance and immune responses of cyclosporine A-treated, immunosuppressed broiler chickens. Br. J. Nut. $p 1$ of 9, doi:10.1017/S000711451100362X2011.

26. Qureshi MA, Havenstein GB. (1994) A comparison of the immune performance of a 1991 commercial broiler with a 1957 randombred strain when fed 'typical' 1957 and 1991 broiler diets. Poult. Sci. 73: 1805-1812.

27. Fathi MM, Ali RA, Qureshi MA. (2003) Comparison of immune responses of inducible nitric oxide synthase (iNOS) hyper- and hypo-responsive genotypes of chickens. Int. J. Poult. Sci. 2: 280-286.

28. SAS Institute. JMP (2009) Ver. 8.0.1, User's Guide. SAS Inst. Inc., Cary, NC.

29. Fasina, Y.O., Thanissery, R.R. (2011) Comparative efficacy of a yeast product and bacitracin methylene disalicylate in enhancing early growth and intestinal maturation in broiler chicks from breeder hens of different ages. Poult. Sci. $90: 1067-1073$.

30. Cruickshank, G. (2002) Boosting performance, health and product quality. Poult. World 21, October, p 16.

31. Tangendjaja, B., Yoon, I. (2002) Effect of yeast culture on egg production and mortality in layer chickens. $\mathrm{p}$ 89. Proceedings of $91^{\text {st }}$ Annual Meeting Abstracts, Newark, DE.

32. Pelicia, V.C., Sartori, J.R., Zavarize, K.C., Pezzato, A.C., Stradiotti, A.C., Araujo, P.C., Mituo, M.A. Madeira, L.A. (2010) Effect of Nucleotides on Broiler Performance and Carcass Yield. Braz. J. Poult. Sci. 12:31-34.

33. Sklan D, Melamed D, Friedman A. (1994) The effect of varying levels of dietary vitamin A on immune response of the chick. Poult. Sci.73:843-847.

34. Asli MM, Hosseini SA, Lotfollahian $\mathrm{H}$, Shariatmadari F. (2007) Effect of probiotics, yeast, vitamin $E$ and vitamin $C$ supplements on performance and immune response of laying hen during high environmental temperature. Int. J. Poult. Sc. 6: 895-900.

35. Yalcin S, Yalcin S, Cakin K, Eltan O, Dagasan L. (2010) Effects of dietary yeast autolysate (Saccharomyces cerevisiae) on performance, egg traits, egg cholesterol content, egg yolk fatty acid composition and humoral immune response of laying hens. J. Sci. Food Agric. 90: 1695-1701.

36. Angel, R., Dhandu, A.S., Applegate, T.J., Christman, M. (2001) Phosphorus sparing effect of phytase, 25hydroxycholecalciferol, and citric acid when fed to broiler chicks. Poult. Sci. 80(Suppl. 1):133.

37. Chae, B.J., Lohakare, J.D., Moon, W.K., Lee, S.L., Park, Y.H., Hahn, T.W. (2006) Effects of supplementation $\beta$-glucan on the growth performance 
and immunity in broilers. Res. Vet. Sci. 80:291-298.

38. Morales-Lopez, R., Auclair, E., van Immerseel, F., Ducatelle, R., Garcia, F., Brufau, J. (2010) Effects of different yeast cell wall supplements added to maize or wheat-based diets for broiler chickens. $B r$. Poult. Sci. 51:399-408.

39. Nilson, A., Peralta, J.M.F., Miazzo, R.D. (2004) Use of brewers yeast (S. .cerevisiae) to replace part of the vitamin mineral premix in finisher broiler diets. XXII Worlds Poult. Congress, Istanbul, Turkey.

40. Santin, E.A, Maiorka Macari, M., Grecco, M., Sanchezi, J.C., Okada, T.M., Myasaka, A.M. (2001) Performance and intestinal mucosa development of broiler chickens fed diets containing Saccharomyces cerevisiae cell wall. J. Appl. Poult. Res. 10: 236-244. 